\title{
Research on Evolution of Sensitive Events Involving Troop
}

\author{
LIU Jia
}

\author{
Department of Management Engineering, Engineering University of PAP, Xi'an 710086, China \\ gege20010228@163.com
}

Keywords: Involving troop; Sensitive event; Evolution; Dissipative structure theory

\begin{abstract}
Sensitive event involving troop is the hot topic causing the attention easily, which will impact on the social harmony and the image of troops, if not to be aware sufficiently or deal appropriately. The evolution of sensitive event involving troop is analyzed adopting the dissipative structure theory, and the rules of development of sensitive event are concluded. Then, the key link to deal with the sensitive event involving troop is seized, which provides the reference to make decision in the emergency disposal.
\end{abstract}

\section{Introduction}

At present, China is in the critical period of reform, which all kinds of sensitive issues meet, people's internal contradictions and other conflicts are intertwined, and many abnormal factors affecting the change to the social stability spring. For the highly developed media and extremely complex public opinion environment, if the information involving military staff or events are spread deliberately or unintentionally, it will cause the extensive concern of public opinion. On condition that the negative emotions, attitudes, positions and views are not given enough attention and response, army development and image will be most likely caused serious influence. Evolution mechanism of sensitive events involving troop is the law of occurrence, development and extinction of events above.

Initially, evolution was a concept of biology, and expressed the genetic traits of biological population were different from its ancestor in order to adapt to the evolution of time and space. Also, it is continuous and random changes in the sense of the generation of biological genetic traits. Later the concept of evolution was applied to other subjects, such as social evolution, economic evolution, cultural evolution and human behavior evolution and so on[1], with the purpose of explaining the operation process and mechanism of the social and economic system.

The evolution mechanism of sensitive events involving troop can be described by the fluctuation and the system entropy of dissipative structure theory.

\section{Analysis on Evolution Mechanism of Sensitive Events Involving Troop Based on Fluctuation}

Dissipative structure theory thinks that if a system is open, nonlinear, and in the non-equilibrium state, when the system continuously exchanges matter and energy with the surrounding environment, until the environment or a certain factor of internal system reaches a certain threshold, this system will change through fluctuation (what is called the non-equilibrium phase change). Then, system structure can change from disorder to coordination[2]. The whole social system is a complex adaptive system, the occurrence of sensitive events involving troop is the system transition from one steady state to another steady state[3], as shown in figure 1. Before point A, abnormal factor disturbed in a small scale, the whole system fluctuated in steady state 1 . The quantity accumulation of abnormal factor reached to the critical point $B$, and the emergency erupted, in this phase, the system fluctuated sharply, until the system reached its peak $\mathrm{C}$. After point $\mathrm{C}$, the amplitude of system fluctuation fall, and the system gradually stable in steady state 2 . 


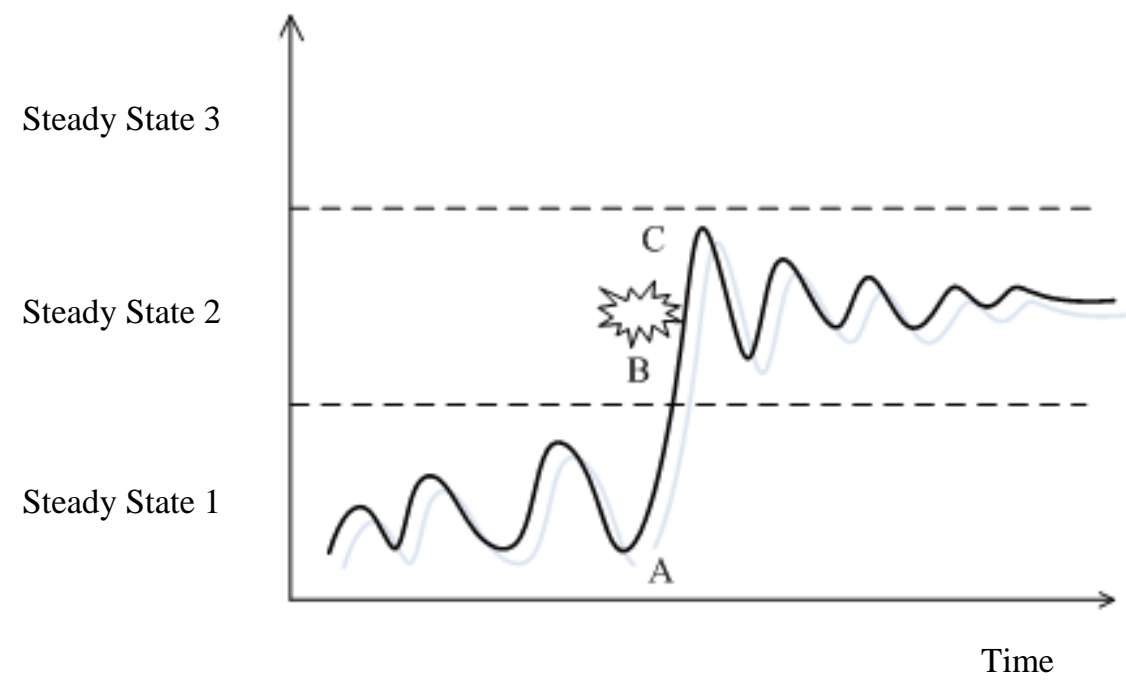

Fig.1 Dissipative structure of development of sensitive event involving troop

Evolution mechanism of fluctuation is shown that quantitative process is usually long and calm, but at the critical point, the qualitative change (or explosion) is more severe. For example, in the case of "Fangdaguo striking airline stewardess", Fangdaguo striking airline stewardess in the flight was the abnormal factor, which disturbed the system in the steady state 1 . This sensitive event involving troop was exposure through micro-blog by the stricken airline stewardess in the afternoon of the day this event happened, when the whole incident information is not complete, and mainly scattered micro-blogs issued by the airline stewardess and the "Finance and Economics" reporter Liweiao. During this period, development of this event showed the characteristics of dispersion, disorder (before point A). The next morning, this airline stewardess posted her injured images in several micro-blogs, and pointed out that the attacker was armed forces commissar FangDaguo in Yuexiu district of Guangzhou city. Then airline stewardess's micro-blogs were forwarded nearly 35000 times and were reviewed nearly 30000, and reporter Liweiao's were forwarded by a lot of famous people. This event began to be concerned by media and net friends. The online public opinion at this time is like the movement hidden in the earth's crust before the eruption, which contains a great amount of energy (approach point B). On the morning of August 30, China civil aviation network published the news "Guangzhou Yuexiu district party committee standing committee armed forces commissar FangDaguo beating China southern airlines flight attendant", rapidly causing highly attention and buzz on internet. With the addition of function of internet marketer, the search index of "FangDaguo" reached 69619, which is shown in figure 1 point $B$ to point $C$, and this process is the most severe stage of the whole event. On January 29, 2013, "Yangcheng Evening News" published the news that Chenhao took on the position of armed forces commissar of Yuexiu district of Guangzhou, which indirectly evidenced FangDaguo has not been in the original position. The event of "Fangdaguo striking airline stewardess" disappeared from media reports since then, and the contradiction and conflict caused by this event come to an end basically, the attention and comments of net friends tend to be calm. The system stabilized to the steady state 2 .

The transition from steady state 1 to steady state 2 means that the cognition of all groups in society has improved. For the public, the cognition of troop was more rational. The processing result of "FangDaguo suspended check" was shown that the troop has strict discipline, which the requirement of military is much stricter than ordinary people, and nobody has privilege. For the army and the government, the enlightenment is that one is strengthening military control, educating officers and men cautious, not to say what shouldn't say, not to do what shouldn't do, not to go where shouldn't go, which prevents hype topic from source; second, to improve response ability facing public opinion's, actively occupy the network battle field, and win the initiative.

\section{Emergency Disposal Strategy of Sensitive Event Involving Troop}

The key link of emergency disposal is found from the evolution process of the sensitive event. 
Grasp the Situation Accurately and Respond Actively. Through the analysis of the evolution based on the fluctuation, it would be found that the early period of the sensitive event involving troop is a process of quantitative change, at this time, if the troop can take the initiative to intervene in the shortest time, the event could be prevented expand and upgrade. Once the sensitive event involving troop happens, the "ostrich" attitude of waiting, relying on, and hiding will only make the problem expand and complex, and lead to loss the best time and conditions for solving the problem. Therefore, troops should actively face up, quickly establish a institution of decision making and command, gain the basic information about the event in time, and determine the nature of event through information processing, so as to determine treatment plan, method and means, etc., and judge and response by tracking the development trend of public opinion, in order to control the situation, release authoritative information to guide public opinion timely, and form a strong positive public opinion.

Deal with Events Decisively and Reduce the Negative Impact. As the special identity of army and soldiers, once the sensitive event involving troop outbreak, it is likely to become a social focus, and its negative influence will form snowball effect easily. If the event is delayed or deal with not properly, not only difficult to quell the storm of public opinion, even will further intensify contradictions, escalation, and ultimately affect the real process of the whole event. In view of the multiple elements, complex relationship and changeable situation, decision-maker should be political acutely and have comprehensive ability to dispose decisively and flexibly through authoritative voice, internal and external control, up and down through adopting corresponding, combining with troops and government, etc. If the problem is too complicated to give a conclusion in a moment, we should publicize the progress of the investigation and the latest developments of the parties, and strive to minimize the loss or negative impact.

Control the Subsequent Public Opinions and Rebuild the Image of the Troops. After the sensitive event enters the attenuation period, the negative effects may still exist, so that still cannot relax. The negative public opinion should be prevented from causing the secondary crisis. In addition, because of the sensitive event involving troop, the troops became the focus for a period of time, and the positive image of troops was damaged to a certain extent under various opinions. At this time, the troops should be brave to admit own shortcomings, summarize the lessons timely, correct and perfect, remodeling public image, and restore the social reputation.

\section{References}

[1] Blackmore S. The Meme Machine [M]. Oxford University Press. 2000.

[2] I. Prigogrin. The End of Certainty. Shanghai Technical Education ed., 1998.

[3] Y Huang, Q Shen, YJ Liu. Microblog Public Opinion Field: A New Perspective for Analyzing Evolution of the Emergency Opinion. Systems Engineering - Theory \& Practice (2015) 2564-2572. (in Chinese)

[4] T Wu, Research on Self-organization. TsingHua University ed, 2001. (in Chinese) 